\title{
Effect of Bolt Number on Joint Stiffness of Disc and Drum Connected by Bolted Joints
}

\author{
H.Y. Wang, Z.Y. Qin, F.L. Chu \\ State Key Laboratory of Tribology \\ Tsinghua University \\ China
}

\begin{abstract}
The disc-drum type rotors are widely used in large turbofan engines, where the drums are connected the adjacent disks with the bolted joints. In this paper, the joint stiffness characteristics of a disc-drum structure are investigated based on the finite element model. Firstly, the nonlinear finite element model for the disc-drum structure is established, where the connecting bolts are modelled and the frictional contact of the joint components is also considered. Then, the variation of joint stiffness of the disc-drum structure with the bolt number subjected to external axial force and bending moment are studied respectively. The works proposed in this paper is helpful to enhance the understanding of the joint stiffness properties of the disc-drum type rotor.
\end{abstract}

Keywords-joint stiffness; bolt number; disc-drum structure; bolted joints; FEM

\section{INTRODUCTION}

The disc-drum type rotors are commonly employed in large turbofan engines, where the drums are used to connect the adjacent discs through the bolted joints and transmit loads [1], as shown in Fig. 1. Due to the existence of contact, friction, gap and other nonlinear factors [2, 3] at the bolted joints, the system stiffness can be greatly reduced, which may affect the mechanical characteristics of the whole structure. Hence, it is of great importance to investigate the variation of joint stiffness properties of the disc-drum structure with various factors, which will help to improve the performance and reliability of the turbofan engines comprising the disc-drum type rotors.

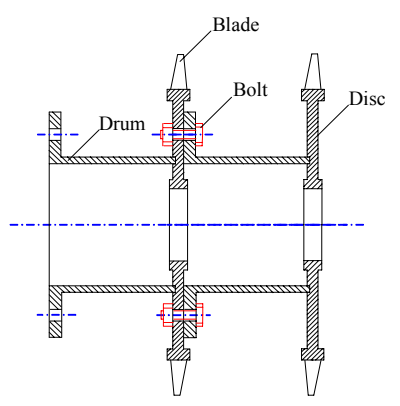

FIGURE I.

\section{SKETCH OF THE DISC-DRUM STRUCTURE.}

Much research has been carried out to study the connection properties of the bolted joints $[4,5]$. Ref. [6] compared the calculation accuracy and efficiency of four kinds of bolt finite element models. Ref. [7] constructed the 3D FE model of a bolted-flange structure, studied the relationship between the axial load and the relative flare angle of the binding surface and discussed the effect of preload and structural parameters.

However, for the structural form of disc-drum connected with bolted joints, there is a few of researches on the joint stiffness characteristics. Actually, many factors can influence the joint stiffness properties, e.g. the geometric parameters of the connected structure, material properties, assembly process, load characteristics, etc. Among various influence factors, the effect of bolt number on joint stiffness properties is mainly concerned in this paper. Firstly, the nonlinear finite element model for the disc-drum structure is established, where the connecting bolts are modelled and the frictional contact of the joint components is also considered. Then, the variation of joint stiffness of the disc-drum structure with the bolt number subjected to external axial force and bending moment are studied respectively.

\section{FINITE ELEMENT MODELLING}

The disc-drum structure from the fan of a certain type aeroengine is investigated in the present paper. The diameter of the drum is $240 \mathrm{~mm}$; the thickness of the drum is $6 \mathrm{~mm}$ and the thickness of the flange is $10 \mathrm{~mm}$. The disc and drum are fabricated from the same steel, whose density is $7850 \mathrm{~kg} / \mathrm{m} 3$, elastic modulus E is $206 \mathrm{GPa}$ and the Poisson's ratio $v$ is 0.3 . There exists frictional contact between the joint components, where the friction coefficient at the contact surfaces is set to be 0.2 .

The FE model of the disc-drum structure is illustrated in Fig. 2, where the disc, drum and bolts are modelled using the brick elements SOLID 185. Since the main purpose of this paper is to analyze the joint stiffness of the disc-drum structure, the blades mounted on the disc are neglected to simplify the analysis procedure. In the model, frictional surface-to-surface contact is defined between each contact pair using contact elements CONTA174 and target segment elements TARGE170. All degrees of freedom (DOFs) on left end surface of the drum are constrained. 


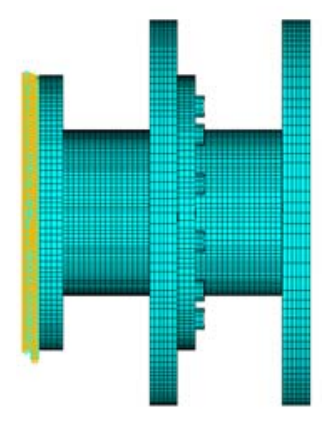

FIGURE II. FE MODEL OF THE DISC-DRUM STRUCTURE.

Considering the effects of nonlinear contact, the analysis process is carried out in three steps as follows: first preloading the connecting bolts using the pretension element PRETS 179; then defining the contact element between the contact surfaces finally performing the nonlinear static analysis subjected to external axial force or bending moment.

\section{JOINT STIFFNESS ANALYSIS}

In order to characterize the joint stiffness, three observation points which are marked as Edge Point, Middle Point and Center Point presented in Fig.3 on the connected surface are selected. The pretension force is set to $80 \mathrm{kN}$ according to Ref. [8]

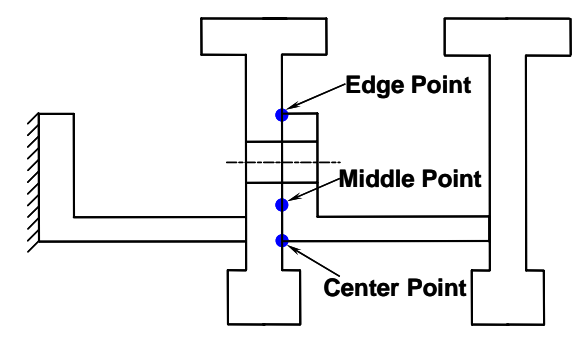

FIGURE III. HREE SELECTED OBSERVATION POINTS

\section{A. Under Tensile Condition}

The finite element model of joint stiffness for the disc-drum structure subjected to external axial load is presented in Fig. 4, and the analysis results are shown in Fig. 5.

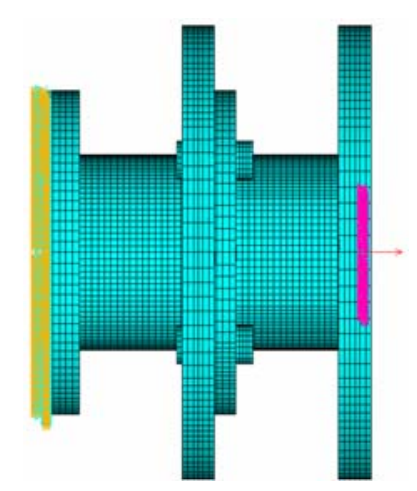

FIGURE IV. THE FEM UNDER TENSILE CONDITION

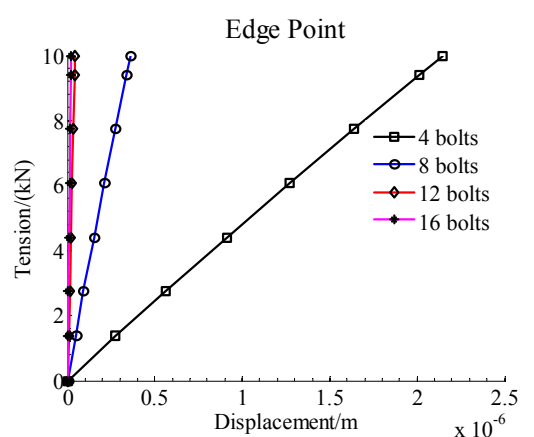

(a)

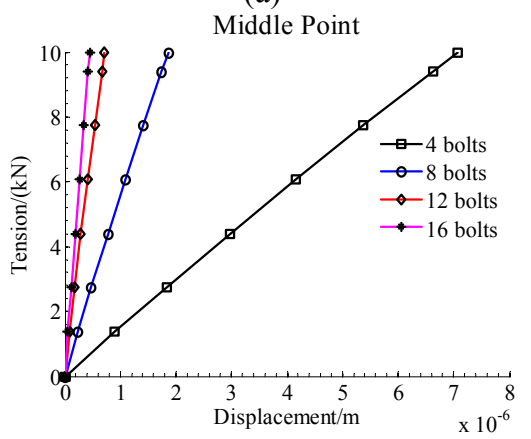

(b)

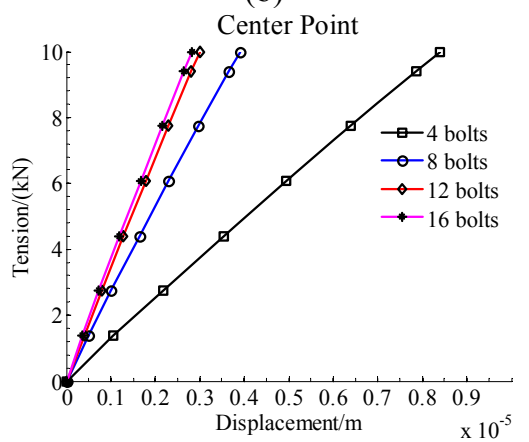

(c)

FIGURE V. FIGURE V. (A) TENSION-DEFORMATION CURVE OF THE EDGE POINT.(B) TENSION-DEFORMATION CURVE OF THE MIDDLE POINT.(C) TENSION-DEFORMATION CURVE OF THE CENTER POINT

It can be seen from fig. 5 that the joint stiffness of the disc-drum structure increases with the increasing of the connected bolt number. And the joint stiffness remains constant when the bolt number is up to 12 .

\section{B. Under Bending Condition}

The finite element model of joint stiffness for the disc-drum structure subjected to external bending moment is presented in Fig. 6, and the analysis results are shown in Fig. 7. 


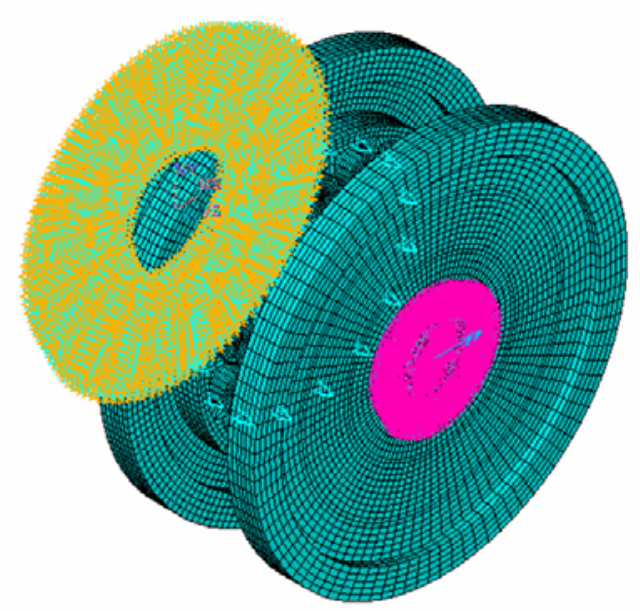

FIGURE VI. THE FEM UNDER BENDING CONDITION

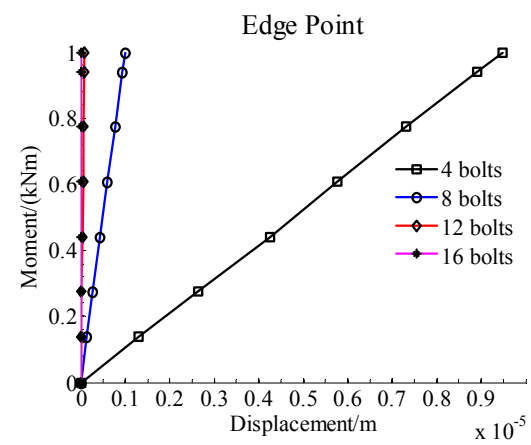

(a)

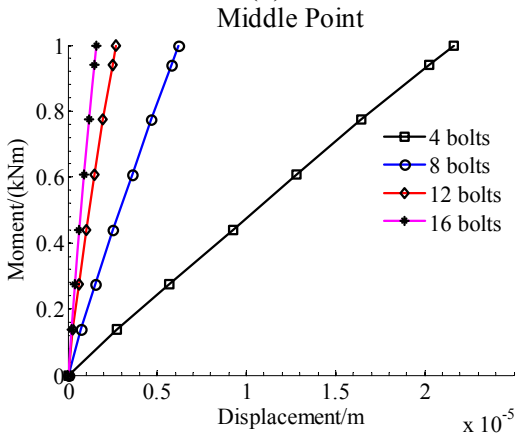

(b)

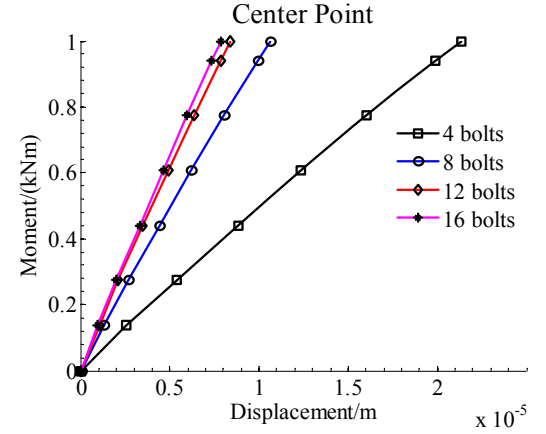

(c)

It can be seen from fig. 7 that the joint stiffness of the disc-drum structure increases with the increasing of the connected bolt number. And the joint stiffness remains constant when the bolt number is up to 12 .

\section{CONCLUSION}

The FEM of the disc-drum structure was developed considering the bolted joints between the disc and drum. The joint stiffness characteristics of the disc-drum structure were investigated, where the effects of the contact friction and preload were accommodated.

It was revealed from the simulation results that the joint stiffness of the disc-drum structure increases with the increasing of the connected bolt number and the joint stiffness remains constant when the bolt number increases to a certain extent.

\section{REFERENCES}

[1] Editorial Board of Aero-engine Design Manual, Aero-engine design manual (19th Part): rotor dynamics and whole engine vibration, Aviation Industry Press: Beijing, pp. 38-39, 2000.

[2] Ferri A A, Modeling and analysis of nonlinear sleeve joints of large space structures. AIAA Journal of Spacecraft and Rockets, 25(5), pp. 354-360, 1988.

[3] Tzou H S \& Rong Y, Contact dynamics of a spherical joint and a jointed truss-cell system. AIAA Journal, 29(1), pp. 81-88, 1991.

[4] Vigh L G \& Dunai L, Finite element modeling and analysis of bolted joints of 3D tubular structures. Computers and Structures, 82, pp. 2173-2187, 2004.

[5] Zhang M, Jiang Y Y \& Lee C H, Finite element modeling of self-loosening of bolted joints. Journal of Mechanical Design, Transaction of the ASME, 129(2), pp. 218-226, 2007.

[6] Kim J, Yoon Joo-Cheol \& Kang Beom-Soo, Finite element analysis and modeling of structure with bolted joints. Applied Mathematical Modelling, 31, pp. 859-911, 2007.

[7] Norman F. Knight, Dawn R. Phillips \& Ivatury S. Raju, Simulating the structural response of a preloaded bolted joint. Proc. of the $49^{\text {th }}$ AIAA/ASME/ASCE/AHS/ASC Structures, Structural Dynamics, and Materials, Reston, pp. 1-20, 2008.

[8] Shaofan Chen, Modern steel structure designer's manual (volume 1), China Electric Power Press: Beijing, pp. 373-374, 2000.

FIGURE VII. (A) BENDING MOMENT-DEFORMATION CURVE OF THE EDGE POINT;(B) BENDING MOMENT-DEFORMATION CURVE OF THE MIDDLE POINT;(C) BENDING MOMENT-DEFORMATION CURVE OF THE CENTER POINT 